\title{
A pentecostalização de povos tradicionais na Amazônia: aspectos conceituais para uma antropologia de identidades religiosas
}

\author{
The Pentecostalization of Traditional peoples in the Amazon: \\ conceptual aspects for an anthropology of religious identities
}

\author{
Donizete Rodrigues * \\ Manoel Ribeiro de Moraes Júnior * *
}

\begin{abstract}
Resumo
Esta comunicação é um trabalho de enquadramento conceitual, que suporta pesquisas etnográficas que enfocam a presença e a dinâmica religiosa do protestantismo-pentecostalismo na Amazônia. A hipótese que estofa epistemologicamente este texto - e os projetos antropológicos já em andamento e futuros - formula a ideia de que o aspecto étnico-cultural "caboclo", como 'tipo ideal' (no sentido weberiano), é um factor crucial nas dinâmicas evangélicas nesta região. Esta construção conceptual está presente, entre outros, em teóricos como Eduardo Galvão, Heraldo Maués, Angélica Mota Maués e João de Paes Loureiro - estudiosos da cultura amazônica. O objetivo é estudar as dinâmicas históricas e registrar, etnograficamente, as manifestações de movimentos missionários, de igrejas (neo)pentecostais e também de grupos menos institucionalizados, materializadas no forte processo de conversão e evangelização de comunidades tradicionais (indígenas, ribeirinhos, caboclos e populações peri-urbanas). O foco é analisar o impacto destas expressões religiosas em diversos tipos de grupos socioculturais amazónicos e de que forma estas comunidades, agora convertidas, ressignificam, criam e desenvolvem novas expressões do sagrado, formando o que estamos a denominar de 'pentecostalismo caboclo'.
\end{abstract}

Palavras-chave: etnogênese; pentecostalismo caboclo; missões evangélicas; pajelança; Amazônia.

Comunicação submetida em 06 de maio de 2018 e aprovada em 03 de agosto de 2018.

* Doutor em Antropologia Social. Professor Associado com Agregação e Diretor do Núcleo de Estudos da Religião da Universidade da Beira Interior. Investigador Sénior do Centro em Rede de Investigação em Antropologia (CRIA- Universidade Nova de Lisboa). País de origem: Portugal. E-mail: donizetti.rodrigues@gmail.com.

** Doutor em Ciências da Religião. Professor da Universidade do Estado do Pará. Diretor do Centro de Estudos e Investigações de Religiões na Amazônia. País de origem: Brasil. E-mail: manoelmoraes@uepa.br

Horizonte, Belo Horizonte, v. 16, n. 50, p. 900-918, maio/ago. 2018 - ISSN 2175-5841 


\begin{abstract}
This paper is a conceptual framework, which support ethnographic fieldwork that focus on the presence and the religious dynamics of Protestant Pentecostalism in the Amazon. The hypothesis that epistemologically sustains this work - and the anthropological research projects already in progress and future - formulates the idea that the "caboclo" ethnic-cultural aspect, an 'ideal type' (in the Weberian sense), is a crucial factor in the dynamics of the evangelical process in this region. This conceptual construction is present in theoreticians, such as Eduardo Galvão, Heraldo Maués, Angélica Mota Maués and João de Paes Loureiro - scholars of Amazonian culture. The objective is to study the historical dynamics and to record ethnographically the manifestations of missionary movements, of neo (Pentecostal) churches and also less institutionalized groups, materialized in the strong process of conversion and evangelization of traditional communities (indigenous, riverine, 'caboclos' and peri-urban people). The focus is to analyze the impact of these religious expressions on different types of Amazon socio-cultural groups and how these communities, new converted, re-signify, create and develop new expressions of the sacred, constituting what we are calling 'caboclo Pentecostalism'.
\end{abstract}

Keywords: ethnogenesis; caboclo pentecostalism; evangelical missions; xamanism; Amazon.

\title{
Introdução: o facto religioso
}

No contexto atual da (pós)modernidade, os estudos sobre o sagrado e suas expressões simbólicas, devido às suas especificidades, são necessariamente interdisciplinares, envolvendo as diversas ciências sociais e as denominadas ciências da religião (RODRIGUES, 2013).

Os estudos da religião, como substrato da cultura, são fundamentais para se compreender o universo humano, a sociedade. Segundo Tillich (2009), as religiões podem ser entendidas a partir de dois princípios fundamentais: o de "substância católica" e o "protestante". O primeiro caracterizaria os aspectos ético-substanciais das tradições religiosas quando encarnadas em ritos, mitos, interditos e um aparato estético-simbólico bastante volumoso. O segundo remete às experiências criativas, místicas e heréticas das religiões, a partir das quais pode-se entender as mutações e inovações nas expressões religiosas.

As representações simbólicas e práticas religiosas são expressões totalizantes de modos de vida, a partir dos quais os grupos se orientam, social e culturalmente 
(BOURDIEU, 1999). Considerando que, como nos ensina Weber (2000), toda teodicéia é reflexo de uma sociodicéia, a religião participa do processo de consagração de estruturas e representações históricas, sociais e culturais de povos e comunidades; no caso deste estudo, de comunidades tradicionais (indígenas, ribeirinhas e caboclas) da Amazônia.

Os estudos sócio-antropológicos neste campo não objetivam a crítica ou a defesa de expressões religiosas específicas nem, por outro lado, uma ideia ampla e unificada de religião. Mais do que afirmar e/ou negar a validade de qualquer das múltiplas expressões religiosas e ações humanas, como nos ensina o mestre Durkheim (1996), deve admitir-se que as esferas constitutivas manifestas nas sociedades (neste caso, tradicionais) encarnam um aspecto bem determinado e existente de ação. Para Weber (2000), cada sistema de ação (Handlungssysteme) revela uma forma de prática e de expressão simbólicas. Neste contexto, a religião é uma esfera cultural que tem em si sistema de ações, na qual os seus participantes articulam tipos específicos de práxis, experiência e significação de mundo (TILLICH, 2009).

Conforme o título denuncia, o nosso estudo de Antropologia da religião insere-se no contexto do protestantismo e pentecostalismo. Assim, é pertinente discutir, em primeiro lugar, estes dois movimentos religiosos que marcaram a história do cristianismo do século XVI e XX, respectivamente.

\section{O Protestantismo e o Pentecostalismo: uma nova experiência religiosa}

Em 1517, a história da religião cristã mudava significativamente; o teólogo Martinho Lutero (1483-1546) publicava as suas 95 teses contra alguns aspectos doutrinais da Igreja Católica, que acabariam não só com a sua hegemonia, mas, também, contribuiriam para o surgimento de um novo e marcante movimento religioso, denominado Protestantismo, que veio Reformar radicalmente o modo como a religiosidade cristã era vivida. Os princípios teológicos que Lutero defendia passavam, essencialmente, pela justificação pela fé, através da graça (sola gratia), 
e pela sola scriptura - a Sagrada Escritura como única autoridade doutrinária, sendo que esta poderia ser interpretada individualmente (livre exame) - e que a salvação é obtida pela fé individual em Cristo (RODRIGUES, 2016).

O Protestantismo, principalmente na sua versão Calvinista, também veio apresentar uma nova teologia quanto ao trabalho, passando este a ser visto como uma vocação dada por Deus e que cada um deveria desenvolver. Assim, é valorizado o esforço individual, a dedicação ao trabalho e não aos prazeres do mundo, muito caracterizado pelo que Weber (2001) denomina de 'ascetismo', um estilo de vida austero e centrado na salvação.

Para resumir: no contexto do protestantismo, há quatro doutrinas fundamentais: a) a salvação somente através da fé em Jesus Cristo; b) a experiência de conversão pessoal, comumente chamada de 'nascer de novo' numa nova espiritualidade; c) a importância das missões e evangelização; e d) a verdade ou inerrância da Sagrada Escritura.

O protestantismo é introduzido já no século XVI nos Estados Unidos, através do processo de colonização, dos imigrantes e missões evangélicas europeias, tornando-se um dos pilares fundamentais na construção da identidade cultural-religiosa da sociedade norte-americana.

É neste substrato teológico protestante norte-americano que surge o pentecostalismo. Este reavivamento religioso começou, em 1901, através de um grupo de fiéis metodistas ${ }^{1}$, da Escola Bíblica de Topeka, no Kansas, sob a liderança de Charles Parham (1873-1929). Reunidos e num forte momento de oração, este grupo sentiu a experiência relatada no Livro de Actos 2: 1-4, em que os apóstolos de Cristo falaram em línguas estranhas (glossolalia), ficando esta experiência conhecida como o batismo de fogo no/do Espírito Santo.

\footnotetext{
${ }^{1}$ O Metodismo, um ramo do Protestantismo, surgiu como um movimento que procurava uma condição de 'cristão perfeito'. Para além da fase inicial da conversão/justificação, também deveria existir uma procura pela 'santificação', vivendo-se longe dos pecados e com uma vida o mais ascética possível.
}

Horizonte, Belo Horizonte, v. 16, n. 50, p. 900-918, maio/ago. 2018 - ISSN 2175-5841 
Este momento de forte expressão religiosa-espiritual iria marcar a história do protestantismo mundial. Um importante discípulo de Parham foi William Seymour (1870-1922), da Igreja dos Nazarenos. Em 1906, o jovem pastor negro iniciou este reavivamento em Los Angeles - num antigo templo da Igreja Metodista Episcopal, no número 312 da Azusa Street -, ganhando rapidamente notoriedade e atraindo uma multidão de fiéis, principalmente negros e imigrantes hispânicos pobres, ou seja, os excluídos das 'igrejas protestantes dos brancos' e da sociedade norte-americana em geral. Deste movimento inicial, surgiram várias pequenas igrejas pentecostais que, em 1914, numa tentativa de unificação teológica e doutrinal, criaram a denominação ‘Assembleias de Deus’.

O reavivamento da Azusa Street atraiu muitos fiéis, mas também pastores, entre eles William Durham, da Igreja Baptista de Chicago. O pastor Durham foi de grande importância para a entrada do pentecostalismo no Brasil - foi na sua igreja que os imigrantes Luigi Francescon (italiano) e Daniel Berg (sueco) tiveram contacto com este reavivamento e de onde saíram como missionários para o Brasil: Francescon funda, em 1910, em São Paulo e no Paraná, a Congregação Cristã; em 1911, Daniel Berg, juntamente com o seu conterrâneo Gunnar Vingren (formado no Seminário Teológico Sueco de Chicago), inicia o movimento pentecostal no Estado do Pará, dando origem as Assembleias de Deus no Brasil (ALENCAR, 2013), assunto que falaremos mais adiante.

A partir dos Estados Unidos, o pentecostalismo protestante expandiu-se rapidamente para outros países e tornou-se num fenómeno global, complexo e de grande diversidade; por isso, hoje fala-se em pentecostalismos, no plural. Sendo uma 'religion on the move', ou seja, com forte mobilidade geográfica - de fiéis, igrejas e missionários - é hoje um dos maiores e mais dinâmicos movimentos religiosos, com mais de 564 milhões de seguidores, sendo o Brasil o país com a maior concentração de pentecostais do mundo (RODRIGUES, 2016).

Mas de que falamos quando falamos de (neo)pentecostalismo(s)? Tentando ser o mais abrangente possível, as principais características da vertente protestante 
deste movimento são: baptismo no/do Espírito Santo; princípio do Deus vivo, que se manifesta ao verdadeiro crente através do Espírito Santo; glossolalia - o carisma de 'falar em línguas'; carisma/dom da cura divina, através da imposição de mãos; a ideia do corpo-impuro, de que as doenças/sofrimento humano são causados pelo(s) diabo/demónios; purificação do corpo através do exorcismo de pessoas possuídas pelo(s) diabo/demónios - 'esvaziamento'/exorcismo do corpo-impuro e preenchimento do corpo (curado) pelo Espírito Santo; líderes carismáticos (no sentido weberiano); milenarista - à espera da segunda vinda de Cristo, que irá salvar a 'sua igreja'; forte proselitismo, com grande visibilidade pública; chamamento espiritual para a missionação; ênfase na evangelização de jovens; fortes manifestações emocionais; utilização da música/dança nos rituais; valorização do bem-estar físico (não consumo de tabaco, álcool, droga); 'bornagain’ - conversão/renascer para uma nova espiritualidade; exclusivismo religioso - pertencer somente a uma igreja; endogamia - 'evangélico só deve casar com evangélico'; a ideia de 'povo escolhido' por Deus/Jesus Cristo e destinados à salvação; 'estar no mundo' (consciência/participação social e política) sem ‘ser do mundo' (vida mundana, de pecado); uso intensivo e eficiente dos meios de comunicação de massas (TV, rádio, jornais e internet-sites oficiais e redes sociais) como meio de proselitismo; utilitarista, buscando a resolução imediata dos problemas espirituais, económicos e de saúde; predominante conservadorismo moral e político; os congregantes são na sua grande maioria: sexo feminino, imigrantes/minorias étnicas no contexto da diáspora, pessoas dos estratos sociais mais baixos; fortíssima ênfase na recolha de dinheiro entre os fiéis (dízimos, ofertas); ênfase na teologia da prosperidade, ritualidade centrada na forte valorização do dinheiro².

Teologicamente, este movimento adota uma vivência religiosa centrada na experiência de Deus, do Espírito Santo, que se revela, sobretudo, pelos dons espirituais da glossolalia e da cura divina. O principal objetivo dos pentecostais é

\footnotetext{
${ }^{2}$ A vertente católica do pentecostalismo partilha muitas destas características. No entanto, considerando os objetivos e o espaço deste texto, não é pertinente falar aqui do movimento de renovação carismática.
}

Horizonte, Belo Horizonte, v. 16, n. 50, p. 900-918, maio/ago. 2018 - ISSN 2175-5841 
recuperar o cristianismo primitivo, baseado na união, na comunidade e, principalmente, na 'experiência física do Espírito', o batismo no/do Espírito Santo. A noção protestante da fé, centrada no indivíduo, é interpretada como uma trajetória que implica mudanças radicais no comportamento dos crentes, tendo estes que 'nascer de novo' (born-again), através da aceitação de Cristo (pela fé) e pelo batismo nas águas (ALBRECHT; HOWARD, 2014).

Com esta sintética (mas pertinente) discussão sobre a origem do protestantismo e do pentecostalismo e as suas principais características, é altura de contextualizar, geográfica e antropologicamente, este estudo.

\section{O Contexto Étnico-Cultural-Religioso da Amazônia}

Desde o século XVI, a exploração econômica da Amazônia foi sempre pautada por uma forte prática extractivista, de produção agro-pastoril de modelo fundiário, por atividades comerciais e industriais e expansão urbana desordenada. Por isso, desde os tempos coloniais, o processo de desenvolvimento econômico tem sido uma das causas principais do genocídio e etnocídio amazônicos (SCHMINK; WOOD, 2012).

Do ponto de vista antropológico, os cinco principais grupos étnico-raciais e socioculturais na formação do povo brasileiro são: 1. os múltiplos povos indígenas (os ameríndios); 2. o branco (miscigenado) português católico; 3. os diversos grupos étnicos africanos negros escravizados; 4. os imigrantes brancos europeus, muitos deles de base protestante (RIBEIRO, 1995); e 5. os asiáticos, com grande destaque para a comunidade japonesa. Com a óbvia maior presença dos indígenas, todos estes grupos contribuíram, significativamente, para a formação do ethos amazônico.

No processo de ocupação e ordenamento do território brasileiro pela coroa portuguesa, a formação populacional aconteceu sob condições de conflitos interétnicos, submissão do indígena à mão de obra numa economia extractivista, 
aldeamento missionário católico como elemento civilizatório e inserção do negro na economia como produto e produtor assalariado, factores que provocaram um acentuado genocídio, etnocídio, assimilacionismo intercultural e severas tensões religiosas.

No que se refere à religião, desde o século XVI, com o monopólio da Igreja Católica, as ordens e paróquias católicas portuguesas exerceram, oficialmente, um papel fundamental na introdução e expansão do cristianismo-romano no Brasil, inclusive entre os povos indígenas, através, principalmente, da atuação dos missionários jesuítas (ALMEIDA, 2006).

E quanto ao protestantismo? Os primeiros contatos entre protestantes e indígenas remontam ao século XVI, com as incursões de francesas huguenotes no Rio de Janeiro e Maranhão e, no século XVII, com os calvinistas holandeses na Bahia e, principalmente, em Pernambuco.

Na altura, predominava na Europa a ideia de que a evangelização não era só uma prática de cristianização do mundo, mas, principalmente, parte de um processo ‘civilizacional'. Seguindo um ‘dever civilizatório', os missionários tinham a incumbência de levar a (sua) 'civilização' (no sentido de Norbert Elias, 1994) aos povos bárbaros. Para isso, os indígenas tinham que abandonar o estágio selvagem e essa transformação só era possível pela mudança religiosa; leia-se, a conversão dos (primitivos) indígenas ao protestantismo 'civilizado' e 'civilizador'. Mas, talvez por causa da 'inconstância da alma selvagem' (VIVEIROS DE CASTRO, 2002), este desígnio do protestantismo não se realizou; pelo menos até ao século XIX (MENDONÇA, 1997; GONÇALVES, 2011).

A espiritualidade do xamanismo indígena, a pajelança, o catolicismo popular, o espiritismo kardecista, os cultos aos orixás e os movimentos protestantes de missões e imigrações entrelaçaram-se num sincretismo culturalreligioso e formaram o ethos brasileiro. É neste cenário que: “O Brasil sincrético dos indígenas, catolicismo e cultos africanos é marcado por uma religiosidade com 
muita abertura para a manifestação do êxtase e suas variantes, onde o pentecostalismo encontra campo fértil” (ALENCAR, 2013, p. 50).

Portanto, é neste contexto multi-étnico-cultural-religioso, de múltiplas e diversificadas religiosidades e espiritualidades, que passam a atuar os movimentos e igrejas pentecostais que, no início do século XX, apareceram na Amazônia (WRIGHT, 2004). Desde então, ocorre, com mais intensidade nas duas últimas décadas, um processo de pentecostalização dos povos indígenas, de diferenciados estágios de integração (aculturação e assimilação) na sociedade brasileira.

Mas antes da chegada dos missionários pentecostais, o protestantismo vindo também dos Estados Unidos e da Suécia - já havia feito a sua incursão na região amazônica, facilitando, de certa forma, a penetração e expansão do pentecostalismo entre as comunidades tradicionais. A base (e a justificativa) teológica da missão proselitista é Marcos 16:15, "ide por todo o mundo e pregai o Evangelho a toda a criatura”, 'incluindo os indígenas da Amazônia', poderíamos acrescentar.

Segundo Vanda Pantoja (2012) - num contexto de forte crise da Igreja Católica na Amazônia, por causa dos conflitos com o poder civil local e com a falta de cleros - o protestantismo foi introduzido nesta região por três protagonistas: o missionário metodista norte-americano Daniel Kidder, em 1839; o capitão norteamericano Robert Nesbit que, entre 1857 e 1858, distribuía bíblias a bordo do seu navio; e, principalmente, o missionário escocês Richard Holden, em 1860, enviado ao Brasil pelo Conselho de Missão da Igreja Episcopal e da Sociedade Bíblica Americana. Holden chegou mesmo a fundar, em Belém, a igreja 'Serviço Bethel'. Após a saída de Holden do Pará, em 1862, a evangelização de base protestante na região é marcada pelos trabalhos missionários das Igrejas Presbiteriana (1878), Metodista e Batista (1897). O pastor metodista era o sueco Justus Nelson, que chegou a Belém em 1885. Outro pastor sueco de relevo foi Erik Nilsson, que fundou a Primeira Igreja Batista de Belém, em 1896. 
É com este substrato protestante norte-americano e sueco que o protestantismo-pentecostal surge na Amazônia (indígena e cabocla), em novembro de 1910, com a chegada dos missionários baptistas suecos Gunnar Vingren e Daniel Berg, vindo dos Estados Unidos, berço do pentecostalismo. Inicialmente, eles começam a ministrar na Igreja Batista local. Porém - e confirmando a forte tendência do protestantismo (e mais ainda do pentecostalismo) para o divisionismo eclesiástico -, eles rompem com esta igreja e criam a 'Missão da Fé Apostólica' (o mesmo nome da igreja criada, em Los Angeles, por William Seymour, em 1906). Em 1917, chega ao Brasil Samuel Nystron, como o primeiro missionário oficialmente enviado pela Igreja Filadélfia de Estocolmo. E assim, em 1918, nasce a denominação ‘Assembleias de Deus do Brasil' (ALENCAR, 2013).

Mas não pretendemos fazer um trabalho de Antropologia das missões; o objetivo deste estudo é procurar entender a forma como as populações tradicionais (principalmente indígenas) da Amazônia, a partir da sua cosmologia, absorvem, interiorizam e ressignificam a religiosidade evangélica.

As condições sociais precárias das populações indígenas, relacionadas com o processo de aculturação/assimilação - com sérios problemas de alcoolismo nos homens e com mulheres no mundo da prostituição, factores que agravam ainda mais a situação e reforçam o estigma social (no sentido goffmaniano) destes grupos -, favorecem a penetração e expansão do pentecostalismo entre os grupos tradicionais; é importante lembrar que este movimento religioso tem nas suas origens a prática de 'salvação espiritual' dos excluídos socialmente.

Ao longo do processo histórico de contato cultural do protestantismo com as populações indígenas, houve várias agências missionárias que desempenharam (e algumas ainda desempenham) um importante papel na evangelização dos povos nativos: 'Summer Institute of Linguistics', 'New Tribes Mission', Missão Novas Tribos do Brasil, Missão Evangélica na Amazônia, Grupo de Trabalho Missionário Evangélico, Igreja Luterana do Brasil e as Juntas ligadas às igrejas Batista, 
Presbiteriana, Metodista e, nomeadamente, Assembleias de Deus (ALMEIDA, 2006).

As denominações evangélicas que trabalham com as populações indígenas atuam segundo dois princípios distintos: ‘inculturação’ e ‘transculturação’. Vejamos as principais diferenças entre estes dois modelos de mediação cultural, materializados num maior e/ou menor respeito pela cultura indígena.

$\mathrm{Na}$ perspectiva da inculturação - com maior sensibilidade antropológica, digamos assim - há um maior respeito e aceitação das tradições culturais e religiosas dos índios por parte dos missionários. Mais do que isso, os missionários servem de intermediários com os brancos e tentam apoiar as populações indígenas na sua luta pela demarcação de terras e ‘autodeterminação' étnica. A partir dos ensinamentos bíblicos - usando, principalmente, o Novo Testamento e personagens chaves do Antigo Testamento -, a ideia é fazer uma partilha de códigos religiosos, ou seja, encontrar na cosmologia nativa elementos (acontecimentos, rituais, crenças) que podem ser traduzidos e adaptados, facilitando, deste modo, a aceitação do cristianismo por parte dos indígenas. E, assim, as populações indígenas, em processo de evangelização, criam a sua própria maneira de viver a nova prática religiosa.

$\mathrm{Na}$ perspectiva da transculturação, ao contrário, a missão é 'salvar' espiritualmente o indígena ('pecador e sem Deus'). Para isso, é preciso converter e remodelar tudo aquilo que é representado como sendo parte do sistema religioso nativo - mitos, ritos, comportamentos, moral, símbolos (ALMEIDA, 2006, p. 287). Ou seja, a partir de uma (necessária) desestruturação da cosmologia original indígena, o objetivo é fazer uma reestruturação da mesma e inserção no modelo religioso evangélico. Nas suas ações proselitistas com os índios, as missões transculturais defendem os seguintes preceitos religiosos: 
Salvacionismo, a expectativa escatológica, a mudança de comportamento via código moral, a introdução de novos rituais, a formação de lideranças religiosas nativas e, por fim, a ênfase na tradução da Bíblia, cujo pressuposto exegético é a interpretação literalista... do texto sagrado (ALMEIDA, 2006, p. 280).

Mas o contexto étnico-cultural-religioso da Amazônia é uma problemática antropológica demasiadamente ampla e complexa, incluindo a sua espacialidade (área geográfica). É preciso, portanto, especificar o nosso primeiro terreno etnográfico: o Estado do Pará. 3

\section{O primeiro terreno etnográfico}

O Estado do Pará, com uma área de 1.247.954.666 km2, é a segunda maior unidade federativa do Brasil. Limita-se com os estados brasileiros do Amazonas (o maior de todos), Mato Grosso, Tocantins, Maranhão, Amapá, Roraima e com os países Guiana e Suriname (cf. Figura 1). A sua capital é Belém, cuja área metropolitana possui cerca de 2.4 milhões de habitantes. No seu território existem 28 diferentes grupos indígenas (alguns divididos em subgrupos, como é o caso dos kayapó), que ocupam uma área de 23.819.186 hectares, com uma população estimada de 15.450 indivíduos.

\footnotetext{
${ }^{3}$ O nosso primeiro interesse antropológico sobre pentecostalização de povos tradicionais na Amazônia começou no Estado do Pará,
} com os Suruí-Aikewara. No entanto, extendemos o estudo para outros Estados, nomeadamente Amapá, Rondônia e Amazonas.

Horizonte, Belo Horizonte, v. 16, n. 50, p. 900-918, maio/ago. 2018 - ISSN 2175-5841 
Figura 1: Mapa do Estado do Pará

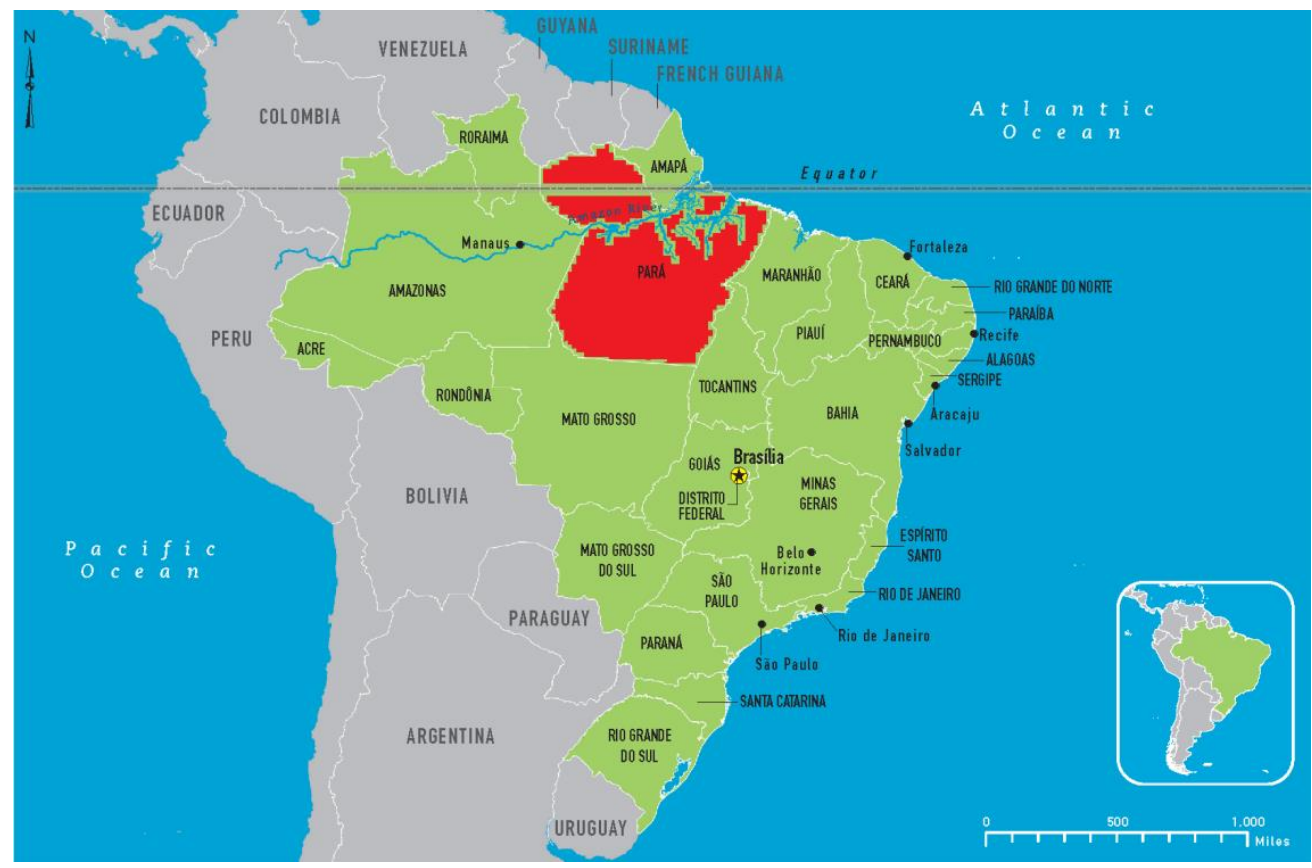

Fonte: Mapsof.net - adaptado

Apoiando-nos em teorias e categorias sociológicas e antropológicas, e a partir de um substrato cultural-religioso amazônico, o objetivo é estudar as dinâmicas históricas e identitárias de movimentos missionários e igrejas (neo)pentecostais, materializadas no forte processo de conversão e evangelização de povos tradicionais (indígenas, ribeirinhos e caboclos). O foco é analisar o impacto destas expressões religiosas em comunidades de cultura ancestral e de que forma estas comunidades, agora convertidas (POLLOCK, 1993), ressignificam, criam e desenvolvem novas expressões do sagrado.

O estudo no terreno apoia-se na metodologia antropológica que tem como base a observação participante e entrevistas semi-diretivas. Como afirmou Geertz (1978), a etnografia é uma técnica de pesquisa que se fundamenta na busca da compreensão do mundo, a partir das categorias dos sujeitos pesquisados, produzindo 'descrições densas'. É isso que estamos a fazer: imersão no terreno 
etnográfico, com discrições e análises de práticas simbólicas de populações indígenas e ribeirinhas evangelizadas, no contexto do que estamos a denominar de ‘pentecostalismo caboclo’ amazônico.

Inspirado nos trabalhos etnográficos de Galvão (1953) e Maués (2005) - e no conceito de imaginário antropológico de Durand (1989) - o pentecostalismo está sendo considerado não somente como uma experiência de efervescência religiosa (no sentido durkheimiano) no contexto evangélico, mas, também, como práticas de convergências imaginárias de múltiplas tradições religiosas regionais. Desta forma, em homologia ao conceito cunhado por Heraldo Maués, de pajelança cabocla tendo origem nas manifestações xamânicas de grupos tupis, é uma forma de culto mediúnico de curandeirismo que incorporou crenças e práticas religiosas do catolicismo popular, kardecistas e africanas - o tipo ideal (no sentido weberiano) a partir do qual se tece teoricamente o campo de pesquisa é o de pentecostalismo caboclo.

Mas o que entendemos por 'pentecostalismo caboclo'? Para melhor explicar este conceito é necessário discutir primeiro o que é o 'caboclo'. A categoria de caboclo é bastante complexa: de representação social negativa e estigmatizada, inclui dimensões geográfica-ecológica (região da Amazônia), étnica-racial (índio destribalizado, desterritorializado, e mestiço do branco-português com ameríndio e com afro-descendente) e de classe (pobre, rural, analfabeto). Outra característica diferenciadora importante é que o caboclo garante a sua subsistência principalmente através da exploração dos recursos (coleta, caça e pesca) da floresta4.

A partir da ideia de caboclo, vejamos agora a nossa proposta para a construção do conceito de 'pentecostalismo caboclo': como uma prática pentecostal, ainda mais sincrética, cada vez mais descentrada dos sistemas tradicionais protestantes que, na região da Amazônia, se dissemina como prática de

\footnotetext{
${ }^{4}$ Para uma discussão mais pormenorizada da categoria de caboclo, ver Lima Ayres (1992) e Harris (1998).
} 
êxtase e cura em contextos comunitários de populações indígenas e índios destribalizados e povos ribeirinhos; os dois últimos inseridos na categoria social de caboclo. Neste contexto de 'pentecostalismo caboclo', as igrejas evangélicas assimilam e ressignificam as formas de curandeirismo ou de xamanismo 5 caboclo e - como práticas de bricolagens (LÉVI-STRAUSS, 1970a) e ascetismo evangélico (WEBER, 2001) - desenvolvem e expressam novas ritualidades e experiências religiosas-espirituais.

O xamã (feiticeiro, curandeiro, mediador entre os espíritos e os seres humanos), que mantém "relações íntimas com as forças sobrenaturais", segundo Lévi-Strauss (1970b, p. 188), tem uma função religiosa-espiritual primordial no grupo, sendo o principal descodificador do sistema de referência simbólico e da visão de mundo indígena (ELIADE, 1964). Por isso, neste jogo semântico e de ressignificação religiosa, o xamã é a fonte privilegiada dos missionários, católicos e evangélicos, para fazer uma incursão na cultura indígena.

Na lógica das missões transculturais (fundamentalistas), no entanto, os espíritos que se manifestam no xamanismo são considerados seres malignos (o Diabo e seus demônios) e a pajelança (indígena) está associada ao espiritismo kardecista e à macumba (do universo das religiões afro-brasileiras); portanto, práticas xamânicas e pajelança não são de Deus e são contrárias aos ensinamentos evangélicos e devem, por isso, ser combatidas e eliminadas.

\footnotetext{
${ }^{5}$ A palavra 'xamamismo' deriva do russo-tungue 'saman'. É um fenómeno mágico-religioso predominante na Ásia Central e Setentrional. Envolvendo magia, crenças em espíritos, concepções mitológicas e técnicas de êxtase, embora em formas variadas, também está presente em quase todas as sociedades primitivas/indígenas do mundo. Mesmo que podendo coexistir com outras práticas mágicas, normalmente, a vida religiosa gira em torno do xamã, um das figuras mais importantes no contexto destas sociedades. Há vários nomes para caracterizar um xamã: 'medicine-man', feiticeiro, mago, curandeiro, pajé, sacerdote, místico. Os xamãs, que podem ser homens (predominante) ou mulheres, são seres 'eleitos' e, como tais, têm acesso a uma forma, a um nível do sagrado que é inacessível ao outros membros do grupo/comunidade/tribo. O xamã tem o dom, a capacidade de se comunicar com mortos, com os espíritos dos antepassados e com espíritos da natureza (animais). Como técnica-êxtase de contato com o sagrado, o xamanismo envolve transe, transmutação e contato com espíritos (inclusive de outros xamãs), de seres míticos e de animais; oferece proteção e cura espiritual e física (conhece as propriedades medicinais das plantas e dos animais). As principais vias de recrutamento (formas de reprodução, digamos assim) dos xamãs são: a) transmissão hereditária do poder/estatuto; b) vocação espontânea 'chamamento' ou escolha por partes dos deuses, dos espíritos. Qualquer que tenha sido o método de seleção (hereditário e/ou chamamento), um xamã só adquire o reconhecimento social após ter recebido instrução de dupla ordem: a) extática, através de sonhos, transes e b) tradicional - técnicas xamânicas, nomes e funções dos espíritos, mitologia e genealogia do clã, linguagem secreta, etc. A investidura de um novo xamã está a cargo dos espíritos e dos velhos mestres xamãs. Como um rito de iniciação (no sentido de van Gennep e Turner), a 'posse' acontece normalmente numa cerimónia pública e constitui por si só um ritual autônomo; no entanto, poderá também ter ocorrido em sonho ou durante um estado de êxtase do iniciado (ELIADE, 1964).
}

Horizonte, Belo Horizonte, v. 16, n. 50, p. 900-918, maio/ago. 2018 - ISSN 2175-5841 
Numa outra lógica, a da inculturação, segundo Capiberibe (2006), referindose à evangelização dos palikur (Amapá), "a força motora da conversão foi certamente o batismo com o Espírito Santo da religião pentecostal, experiência de êxtase religioso que possui um forte élan xamânico" (p. 307); ou seja, "a relação entre a experiência do transe xamânico e a experiência do transe pentecostal parece ser a chave que abriu as portas à religião cristã evangélica” (p. 338).

\section{Considerações Finais}

No contexto amazônico, o pentecostalismo apresenta duas características de grande interesse antropológico, que estamos tentando entender:

a) As igrejas evangélicas, principalmente as Assembleias de Deus, dialogam com as culturas locais indígenas (possuidoras de crenças milenárias) e ribeirinhas, estratégia facilitadora no processo de conversão (PANTOJA, 2011). É importante lembrar que este processo dialogante inclui a tradução da Bíblia (uma narrativa escrita) para línguas nativas, marcadamente de cariz oral.

b) Após a conversão evangélica, as populações indígenas e ribeirinhas "não deixam de trazer consigo práticas e crenças de seu antigo repertório culturalreligioso" (PANTOJA, 2011, p. 117), as suas narrativas míticas e expressões do sagrado. Ou seja, a partir dos seus processos culturais originais, os indígenas reinventam, ressignificam, transformam a tradição escrita (a Bíblia) numa oralidade própria (REIS, 2015), ajudando, desta forma, a transformar o pentecostalismo de matriz protestante num 'pentecostalismo caboclo'.

Os pentecostalismos caboclos na Amazônia têm como estofo as práticas da pajelança cabocla, logo e também, uma intimidade eletiva com suas práticas xamânicas de magia e êxtase. A cura, a profecia, as expressões linguístico-extáticas, etc. O imaginário antropológico do pajé expressa-se no líder religioso e também naquela ou naquele que "ora" sem querer romper com as eclesiocentrias dos 
diversos movimentos evangélicos constituídos. Afinal, a prática da cura e dos êxtases podem ser vistos nos relatos bíblicos dos apóstolos e do próprio Cristo (MAUÉS, 2005).

Tendo por base a categoria de 'tipo-ideal' de Max Weber (2000), recurso metodológico que ajuda na análise e compreensão da realidade social e religiosa, os 'tipos-ideias' do nosso estudo são os seguintes: o protestantismo é o sacerdote (institucionalizado), o pentecostalismo é o profeta (carismático) e o indígena é o feiticeiro (magia xamânica).

A abordagem sobre xamanismo e pentecostalismo leva-nos à seguinte reflexão (ou melhor, constatação) antropológica: o xamã (pajé) indígena e o pastor evangélico, embora fazendo parte de sistemas simbólicos-religiosos distintos, fazem parte da mesma categoria, a de mediadores espirituais, ligando o imanente ao transcendente. Ambos têm a capacidade de se comunicar com espíritos (malignos e benignos) - o pastor pentecostal no exorcismo também não fala com os demónios? Os espíritos dos antepassados e o Espírito Santo não são ambos espíritos? Na lógica da eficácia simbólica lévi-straussiana, xamã e pastor são operadores rituais capazes de curar, física e espiritualmente, as pessoas. Por isso, a passagem do xamanismo para o pentecostalismo é um processo facilitado de tradução cultural: a partir do seu sistema simbólico e cosmologia xamânica, os índios absorvem, interiorizam e ressignificam o pentecostalismo, criando, assim, novas expressões do sagrado, neste caso, evangélicas.

\section{REFERÊNCIAS}

ALENCAR, Gedeon. Matriz Pentecostal Brasileira: Assembleias de Deus, 1911-2011. Rio de Janeiro: Editora Novos Diálogos, 2013.

ALBRECHT, Daniel; HOWARD, Evan. Pentecostal Spirituality. In: ROBECK, Cecil M. JR \& YONG, Amos (Ed.). The Cambridge Companion to Pentecostalism. New York: Cambridge University Press, 2014. p. 235-253. 
ALMEIDA, Ronaldo de. Tradução e Mediação: missões transculturais entre grupos indígenas. In: Paula Montero (Org.). Deus na Aldeia: missionários, índios e mediação cultural. São Paulo: Editora Globo, 2006. p. 277-304.

BOURDIEU, Pierre. A Dominação Masculina. Rio de Janeiro: Bertrand Brasil, 1999.

CAPIBERIBE, Artionka. Sob o Manto do Cristianismo: o processo de conversões palikur. In: Paula Montero (Org.). Deus na Aldeia: missionários, índios e mediação cultural. São Paulo: Globo, 2006. p. 305-342,

DURAND, Gilbert. As Estruturas Antropológicas do Imaginário. Lisboa: Editorial Presença, 1989.

DURKHEIM, Émile. As Formas Elementares da Vida Religiosa. São Paulo: Martins Fontes, 1996.

ELIADE, Mircea. Shamanism: archaic techniques of ecstasy. Princeton: Princeton University Press, 1964.

ELIAS, Norbert. O Processo Civilizador: uma história dos costumes. Rio de Janeiro: Zahar, 1994.

GALVÃO, Eduardo. A vida religiosa do caboclo da Amazônia. Boletim do Museu Nacional, Nova Série, Antropologia, Rio de Janeiro, n. 15, p. 1-18, 1953.

GONÇALVES, Carlos Barros. Até aos Confins da Terra: o movimento ecumênico protestante no Brasil e a evangelização dos povos indígenas. Dourados: Ed. UFGD, 2011.

GEERTZ, Clifford. A Interpretação das Culturas. Rio de Janeiro: Zahar, 1978.

HARRIS, Mark. What it means to be a caboclo: some critical notes on the construction of Amazonian caboclo society as an anthropological object. Critique of Anthropology, Manchester, v. 18, n. 1, p. 83-95, 1998. http://DOI:10.1177/0308275X9801800104

LEVI-STRAUSS, Claude. O Pensamento Selvagem. São Paulo: Editora Nacional, 1970a.

LÉVI-STRAUSS, Claude. Antropologia Estrutural. Rio de Janeiro: Tempo Brasileiro, 1970b.

LIMA AYRES, Deborah de Magalhães. The Social Category Caboclo: the History, Social Organization, Identity and Outsider's Social Classification of the Rural Population of an Amazonian Region (the Middle Solimões). Cambridge, 1992. 327 f. Tese (Doutorado em Antropologia) - Department of Social Anthropology, University of Cambridge.

MAUÉS, Raymundo Heraldo. Um aspecto da diversidade cultural do caboclo amazônico: a religião. Estudos Avançados, São Paulo, v. 19, n. 53, p. 253-272, 2005. Disponível em: http://dx.doi.org/10.1590/So103-40142005000100016. Acesso em: 5 jul. 2018. 
MENDONÇA, António Gouveia. Protestantes, Pentecostais e Ecumênicos: o campo religioso e seus personagens. São Bernardo do Campo: UMESP, 1997.

PANTOJA, Vanda. Santos e Espíritos Santos, ou católicos e evangélicos na Amazônia Marajoara. Bélem, 2011. 223 f. Tese (Doutorado em Antropologia) Universidade Federal do Pará.

PANTOJA, Vanda. Amazônia: terra de missão, bispos ultramontanos e missionários protestantes na Belém do século XIX. Debates do NER, Porto Alegre, ano 13, n. 21, p. 95122, jan/jun, 2012. http://dx.doi.org/10.1234/dner.v2i21.25677

POLLOCK, David. Conversion and 'community' in Amazonia. In: HEFNER. Robert (Ed.). Conversion to Christianity: historical and anthropological perspectives on a great transformation. Berkeley: University of California Press, 1993. p. 165-198.

REIS, Gustavo Soldati. Entre o Oral e o Escrito: missões evangélicas junto aos povos indígenas - uma análise a partir de Michel Certeau. PLURA - Revista de Estudos de Religião, Juiz de Fora, v. 6, n. 2, p. 49-68, 2015. http://DOI:10.18328/21790019/plura.v6n2p49-68

RIBEIRO, Darcy. O Povo Brasileiro. A formação e o sentido do Brasil. São Paulo: Companhia das Letras, 1995.

RODRIGUES, Donizete. O Que é Religião? A visão das ciências sociais. São Paulo: Editora Santuário, 2013.

RODRIGUES, Donizete. O Evangélico Imigrante: o pentecostalismo brasileiro salvando a América. São Paulo: Fonte Editorial e EdUEPA, 2016.

SCHMINK, Marianne; WOOD, Charles H. Conflitos Sociais e a Formação da Amazônia. Belém: EDUFPA, 2012.

TILLICH, Paul. Teologia da Cultura. São Paulo: Fonte Editorial, 2009.

VIVEIROS DE CASTRO, Eduardo. A Inconstância da Alma Selvagem. São Paulo: Cosac \& Naif, 2002.

WEBER, Max. Economia e Sociedade: fundamentos de sociologia compreensiva. Brasília: Editora Universidade de Brasília, 2000.

WEBER, Max. A Ética Protestante e o Espírito do Capitalismo. Lisboa: Editorial Presença, 2001.

WRIGHT, Robin (Org.). Transformando os Deuses: Igrejas evangélicas, pentecostais e neopentecostais entre os povos indígenas no Brasil. Campinas: Unicamp, 2004. v. 2. 